\title{
PEMODELAN OOAD APLIKASI PREDIKSI HARGA SEMBAKO BERBASIS ANDROID
}

\author{
${ }^{[1]}$ Siti Mujilahwati, ${ }^{[2]}$ Suci Nur Fauziah \\ ${ }^{[1],[2]}$ Universitas Islam Lamongan
}

\begin{abstract}
Abstrak :Aplikasi prediksi yang akan dibuat merupakan aplikasi yang dapat membantu memberikan referensi kenaikan / turnnya harga sembako setiap waktu. Aplikasi yang akan dibuat bersifat mobile dengan basis android sehingga semua masyarakat dapat menggunakannya. Pentingnya sebuah analisis permasalahan dalam pembuatan sistem aplikasi prediksi harga berbasis android adalah untuk memberikan arahan petunjuk dan juga ketepatan dalam membuat aplikasi tersebut. OOAD (Object Oriented Analisya and Desain) merupakan sebuah metode untuk memberikan arahan dan petunjuk dalam menciptakan aplikasi bagi programmer, dimana OOAD mampu memanipulasi objek-objek yang terlibat serta sub-sub sistem yang dibutuhkan. Dalam artikel ini akan dibahas desain UML (Unified Modeling Language) untuk sebuah aplikasi prediksi harga sembako berbasis android meliputi, use case diagram, class diagram, activity diagram dan juga sequence diagram. Penelitian ini merupakan tahapan awal dari implementasi aplikasi prediksi yang diharapkan aplikasi tersebut mampu membantu para masyarakat luas dalam memantau harga sembako.
\end{abstract}

Kata Kunci : OOAD, Aplikasi Android, Prediksi, Sembako

\section{Pendahuluan}

Kondisi harga sembako hampir setiap hari mengalami perubahan harga, meskipun kenaikan harga tidak begitu banyak akan tetapi kenaikan itu sangat terlihat ketika kita membuka data harga sembako yang telah dirilis oleh kementerian perdagangan Indonesia. Kenaikan harga yang cukup sigifikan adalah ketika menjelang hari-hari besar atau saat musim panen. Mengetahui kenaikan harga atau memprediksi kenaikan harga sebelum jauh-jauh hari akan sangat membantu bagi pengusaha maupun masyarakat luas dalam memprediksikan kebutuhannnya.

Seiring perkembangan teknologi mobile yang semakin cepat, terutama pada sistem operasi android. Maka membuat para competitor menciptakan beragam aplikasi startup yang dapat memudahkan para user dalam bidang bisnis, edukasi, hiburan, social media bahkan aplikasi-aplikasi yang bersifat informasi atau iklan. Begitu pula yang akan dilakukan oleh peneliti, dimana akan membuat sebuah aplikasi yang nantinya dapat dimanfaatkan oleh masyarakat luas dalam mengetahui dan memantau kenaikan harga sembako.

OOAD adalah metode terstruktur untuk menganalisis, merancang sistem dengan menerapkan konsep berorientasi objek, dan mengembangkan serangkaian model sistem grafis selama siklus hidup pengembangan perangkat lunak (Gabry, 2017). Konsep ini sangat baik dan sesuai dengan metode penelitian dengan menggunakan model water fall, dan pada konsep ini bertujuan menekankan pada pembuatan model sistem, untuk itu pada paper ini fokus dari penelitian dan yang akan dibahas pada artikel ini adalah membuat desain OOAD (Object Oriented Analisya and Desain) dengan UML dimana hasil penelitian ini akan dibuat sebagai dasar implementasi aplikasi prediksi harga sembako yang nantinya dapat dimanfaatkan oleh semua masyarakat 


\section{Metode Penelitian}

Teknik penelitian ini akan menggunakan action research dengan model SDLC (Sistems Development Life Cycle). Dengan menggunakan model SDLC ini diharapkan mampu memberikan arahan peneliti dalam membangun sebuah aplikasi prediksi, pada tahap desain sistemakan dibuat model OOAD(Object Oriented Analisya and Desain). Dimana pada penelitian ini terlebih dahulu akan dilakukan analisis permasalahan dan data, serta desain sistem, implementasi, uji coba dan tahap pemeliharaan. Adapun bahasan pada artikel ini pada tahap analisis dan desain sistem. Pemodelan merupakan bagian paling penting dalam analisis dan desain sistem(Satzinger, 2012).

\section{A. Analisis Sistem}

Analisis sistem dilakukan untuk tujuan mempelajari suatu sistem atau bagian-bagiannya untuk mengidentifikasi tujuannya. Ini adalah teknik pemecahan masalah yang meningkatkan sistem dan memastikan bahwa semua komponen sistem bekerja secara efisien untuk mencapai tujuan. Analisis kebutuhan aplikasi ini akan dilakukan dengan cara ;

1. observasi yaitu dengan pendekatan kepada masyarakat tentang respon kenaikan harga sembako, selanjutnya akan dilakukan wawancara dan respon tentang usulan aplikasi yang akan dibuat. Dari sini akan kita ketahui betapa pentingnya aplikasi yang akan dibuat bagi masyarakat, serta menilai kelayakan user.

2. Literasi data harga sembako dari beberapa tahun terakhir sebagai dasar acuan harga naik atau turun. Pada penelitian ini akan digunakan sebuah metode regresi linier untuk menilai harga sembako tersebut naik apa turun. Sehingga data harga sembako yang ada akan dijadikan data sample/ data latih.

Selain analisis kebutuhan sistem juga memiliki analisis fungsionalitas yaitu adanya tampilan menu user untuk memilih jenis bahan pokok sembako, melihat hasil prediksi terakhir, melakukan prediksi, menginputkan harga jenis sembako terahir dan melihat hasil prediksi yang diinginkan.

\section{B. Desain Sistem}

Sistem desain pada dasarnya merupakan kumpulan aturan, batasan, dan prinsip, yang diimplementasikan dalam desain dan kode. Ketiga atribut ini melayani fungsi yang berbeda dan memberikan keteraturan sistem yang koheren dalam sistem dari tombol ke aplikasi halaman tunggal (L, 2011)

1. Aturan: harus memiliki isyarat visual atau teks untuk menunjukkan CTA

2. Batasan: hanya dapat memiliki 3 jenis unik - utama, sekunder, dan default.

3. Prinsip: harus digunakan untuk interaksi pengguna tertentu

Berdasarkan hasil analisis maka akan dibuat pemodelan desain sistem. Desain sistem mengacu pada konsep OOAD maka akan dibuat sebuah Use Case Diagram, Class Diagram, Activity Diagram serta Sequence Diagram yang akan dibangun dengan UML.

\section{Hasil dan Pembahasan}

UML (Unified Modeling Language) merupakan sebuah standart Bahasa dalam industry visualisai, merancang dan mendokumentasikan sebuah perangkat lunak yang dipakai oleh professional IT dalam membuat aplikasi(Bell, 2003). Desain sistem yang telah dibuat untuk aplikasi prediksi harga sembako berbasis android adalah sebagai berikut : 


\section{A. Use case Diagram}

Tujuan utama dari diagram use-case adalah untuk membantu tim pengembangan memvisualisasikan persyaratan fungsional suatu sistem, termasuk hubungan "aktor" (manusia yang akan berinteraksi dengan sistem) untuk proses-proses penting, serta hubungan di antara yang berbeda(Bell, 2003). Perilaku sistem adalah bagaimana sistem beraksi dan bereaksi. Perilaku ini merupakan aktifitas sistem yang bisa dilihat dari luar dan bisa diuji.Perilaku sistem ini dicapture di dalam USE CASE. USE CASE sendiri mendeskripsikan sistem, lingkungan sistem, serta hubungan antara sistem dengan lingkungannya(arifwicaksanaa, 2016).Desain use case didasarkan atas aktor yang terlibat, aplikasi murni digunakan oleh konsumen masyarakat luas, aplikasi bebas digunakan oleh siapa saja. Sehingga dalam desain ini hanya ada satu aktor yaitu konsumen.

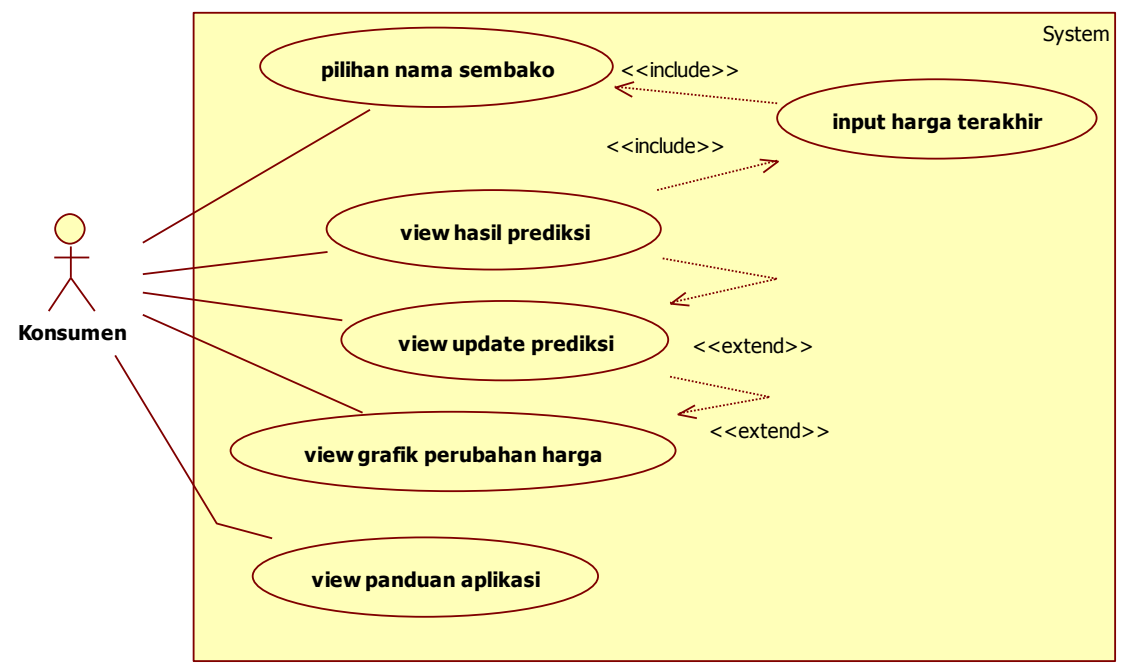

Gambar 1. Use Case Diagram

Dari desain use case tersebut maka dapat dijelaskan bahwa fitur yang diberikan sistem adalah konsumen dapat memilih jenis sembako yang ingin mereka prediksi, sebelum melakukan perhitungan prediksi konsumen diminta untuk menginputkan nilai harga terakhir dari jenis sembako yang ingin diprediksi. Fitur selanjutnya adalah dapat melihat hasil prediksi yang telah dilakukan prediksi sebelumnya. Selain melihat prediksi harga secara numerik maka konsumen dapat melihat hasil prediksi secara grafik. Konsumen yang belum pernah menggunakan aplikasi dapat membuka fitur view panduan.

\section{B. Class Diagram}

Diagram kelas adalah cara yang kuat dan sering digunakan untuk memahami dan mendokumentasikan persyaratan informasi dari suatu sistem(Satzinger, 2012).Class diagram menggambarkan untuk pemrograman berorientasi objek. Dikarenakan pembuatan aplikasi ini dibangun dengan menggunakan android studio yang dasar pemrogramannya juga mengggunakan konsep OOP.Class diagram merupakan salah satu diagram utama dari UML untuk menggambarkan class atau blueprint object pada sebuah sistem. Analisis pembentukan class diagram merupakan aktivitas inti yang sangat mempengaruhi arsitektur piranti lunak yang dirancang hingga ke tahap pengkodean (John W, 2012). 


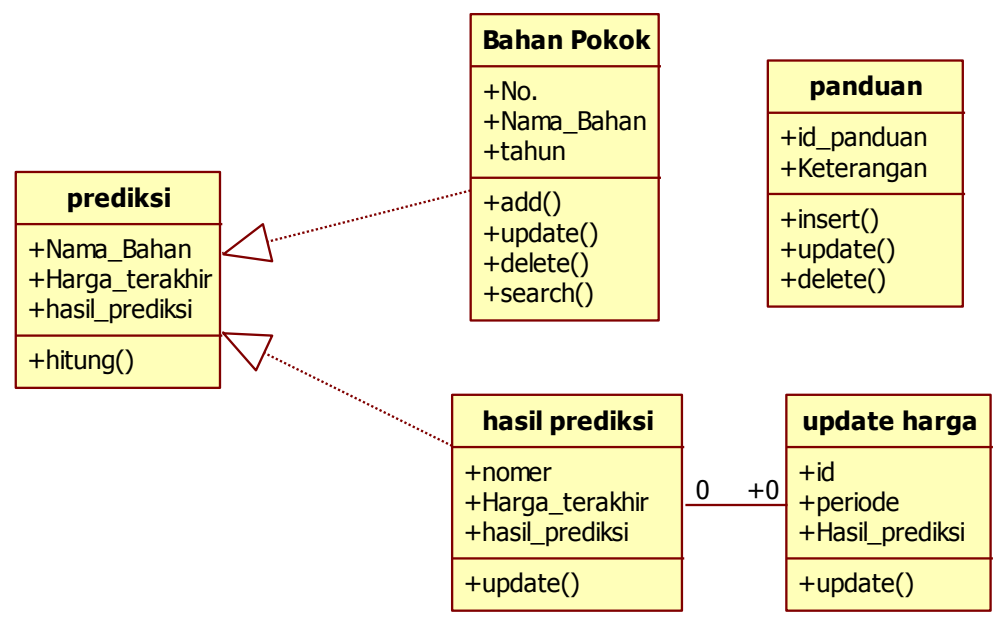

Gambar 2. Class Diagram

Relasi yang digunakan pada class-class diatas adalah relasi assosiasi dan realisasi dengan artinya kelas yang dari bahan pok dan hasil prediksi relasi dari kelas prediksi, mulai dari data, proses dan hasil. Class update harga adalah class yang akan mendokumentasikan hasil prediksi yang diperoleh. Sedangkan class panduan tidak berelasi dikasrena berdiri sendiri bukan dari aksi, dan proses lainnya.

\section{Activity Diagram}

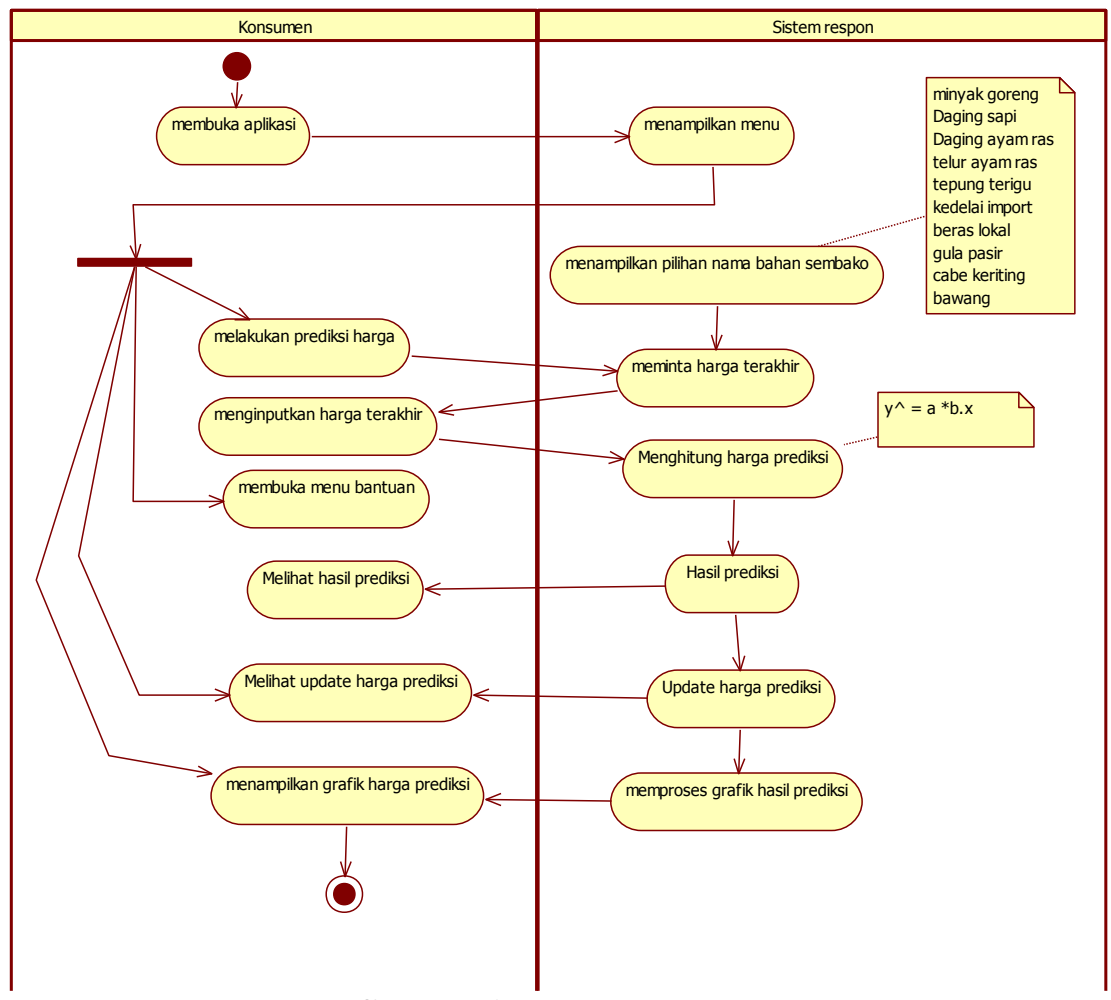

Gambar 3. Activity Diagram 
Sesuai dengan namanya diagram ini menggambarkan tentang aktifitas yang terjadi pada sistem. Dari pertama sampai akhir, diagram ini menunjukkan langkah - langkah dalam proses kerja sistem yang kita buat. Struktur diagram ini juga mirip dengan flowchart. Fungsi Activity Diagram menggambarkan proses bisnis dan urutan aktivitas dalam sebuah proses, Memperlihatkan urutan aktifitas proses pada sistem, Activity diagram dibuat berdasarkan sebuah atau beberapa use case pada use case diagram (Pratama, 2016). Diagram aktivitas sangat membantu ketika alur kegiatan untuk kasus penggunaan sangat kompleks (Satzinger, 2012). Use case Mengisi keranjang belanja yang rumit dalam tiga kasus penggunaan lain yang mungkin diminta saat menambahkan item ke keranjang belanja. Misalnya, aktor mungkin mencari produk dan kemudian melihat ulasan produk sebelum menambahkan item ke keranjang. Setelah item ditambahkan, aktor mungkin mencari dan melihat aksesori yang tersedia dan kemudian menambahkan satu atau lebih ke keranjang.

Activity diagram dibuat supaya programmer dapat mengimimplemkan sesuai dengan alur aktifitas yang akan direncanakan pada aplikasi. Mulai dari aktor atau konsumen melakukan aktifitas sampai aktifitas sistem respon.

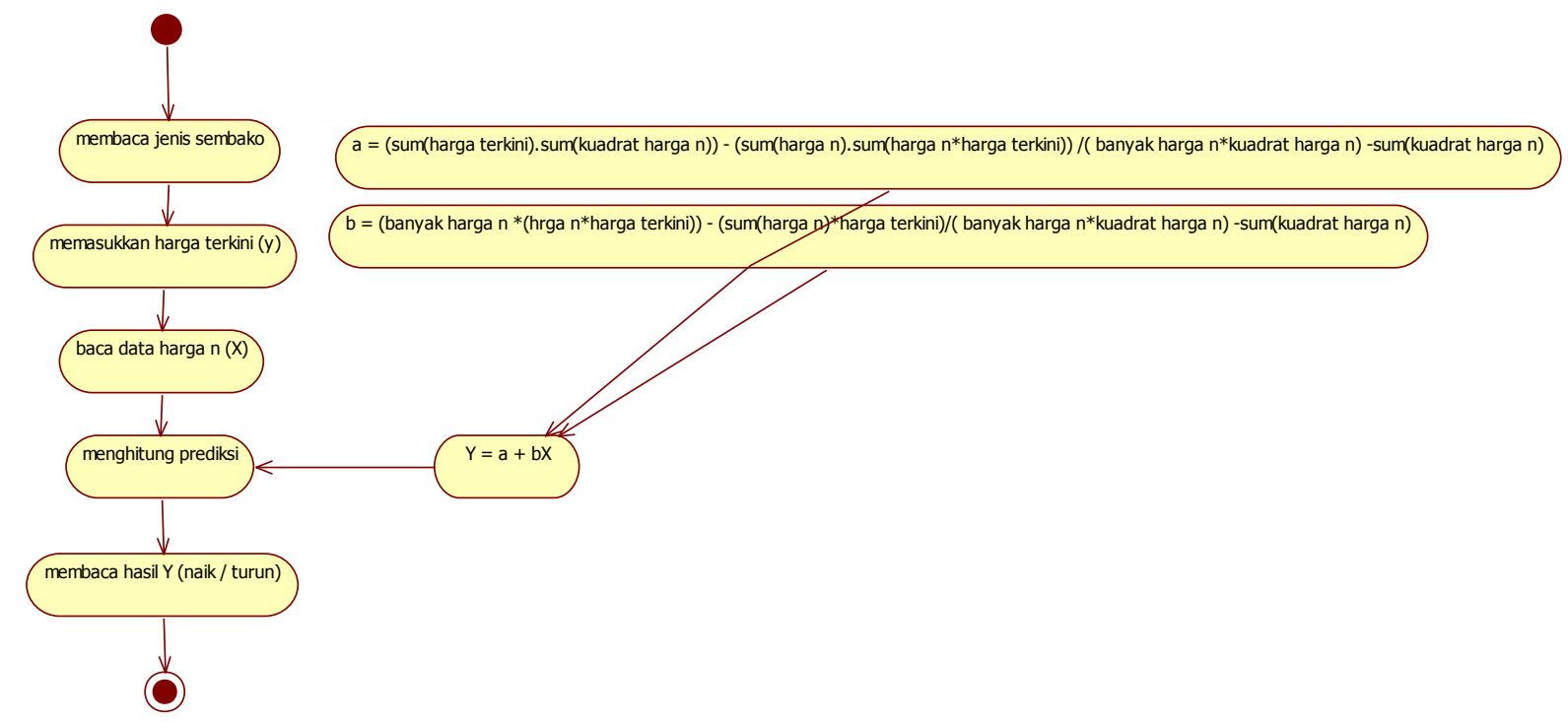

Gambar 4. Activity Regresi Linier

Penggambaran proses regresi untuk prediksi harga sembako dibuat seperti pada Gambar 4 di atas. Dimana regresi membaca dari harga terkini yang dimasukkan oleh konsumen untuk membaca prediksi jenis harga sembako yang akan diprediksi dengan data latih / data harga beberapa tahun terakhir yang dipakai.

\section{Sequence Diagram}

Sequence Diagram adalah salah satu dari diagram - diagram yang ada pada UML, sequence diagram ini adalah diagram yang menggambarkan kolaborasi dinamis antara sejumlah object. Kegunaannya untuk menunjukkan rangkaian pesan yang dikirim antara object juga interaksi antara object. Sesuatu yang terjadi pada titik tertentu dalam eksekusi sistem.Dalam sequence diagram, setiap object hanya memiliki garis yang digambarkan garis putus-putus ke bawah. Pesan antar object digambarkan dengan anak panah dari object yang mengirimkan pesan ke object yang menerima pesan. 


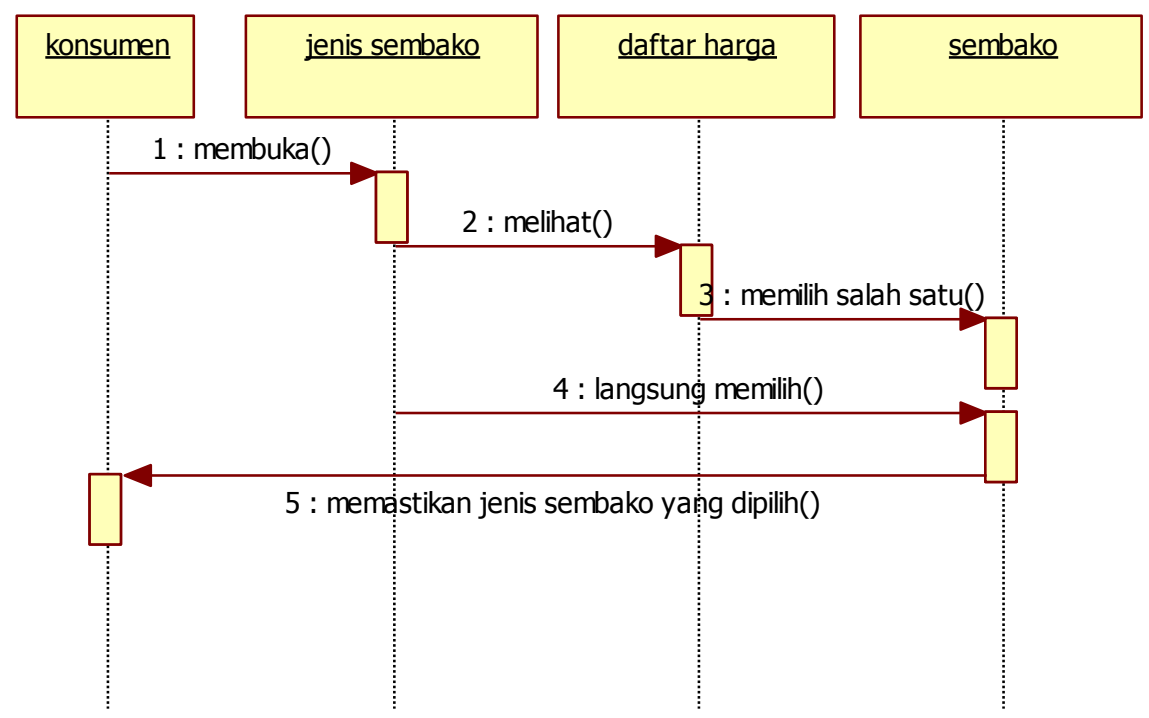

Gambar 5. Sequence Pemilihan Jenis Sembako

Pada sequence diagram diatas, bisa dilihat bahwa yang menjadi aktor adalah konsumen. Setiap aktifitas yang dilakukan oleh konsumen pada proses pemilihan jenis sembako yang akan diprediksi disimbolkan dengan simbul alir secara vertikal oleh garis lurus. Dimulai dari membuka aplikasi sampai memilih salah satu jenis sembako yang telah disediakan oleh sistem diantara ada gading, dagang ayam, beras, bawang, minyak goring, dll sebanyak 11 jenis sembako yang nantinya akan digunakan pada aplikasi prediksi ini. Setelah konsumen memilih jenis sembako yang dipilih selanjutnya adalah konsumen diminta untuk memasukkan harga terakhir / harga saat ini dari jenis sembako yang telah dipilih. Gambaran sequence selanjutnya masuk pada sequence pada proses konsumen melakukan prediksi seperti pada gambaran 6 berikut ini.

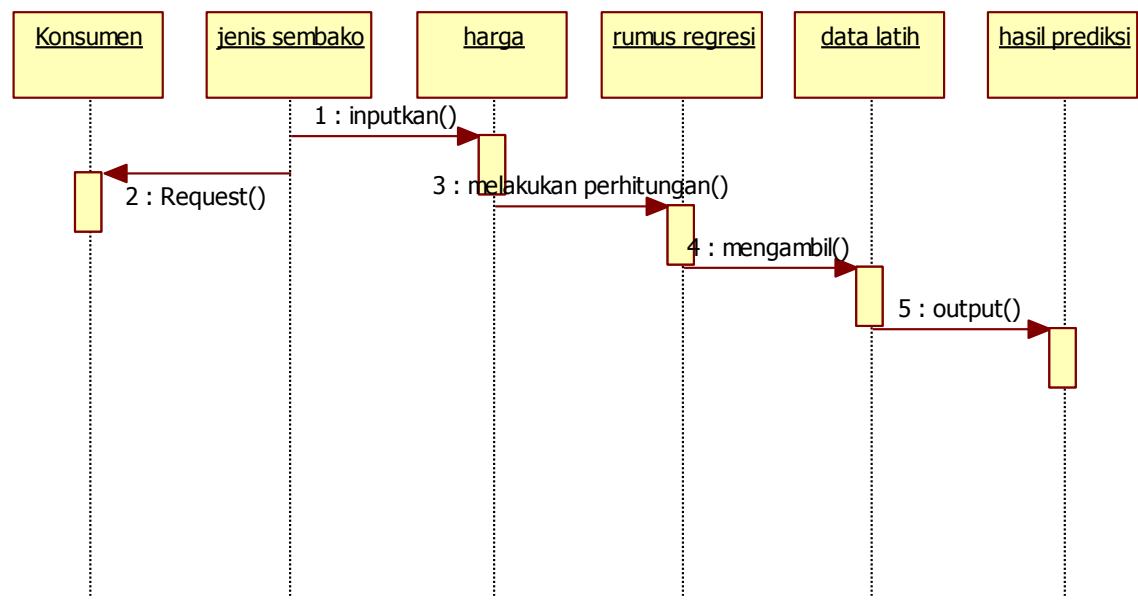

Gambar 6. Sequence Prediksi Harga

Kelanjutan dari proses pemilihan jenis sembako selanjutnya pada Gambar 5 konsumen diminta sistem untuk memasukkan harga sembako terakhir dan system selanjutnya melakukan perhitungan regresi dengan membaca nilai harga yang diinputkan sebagai nilai $\mathrm{x}$ dengan data latih yang telah disediakan oleh sistem. Selanjutnya didapatkan hasil prediksi. 


\section{SimpUlan DAN SARAN}

Dalam tulisan ini, kami mempresentasikan studi kasus pada desain aplikasi prediksi harga sembako berbasis android dengan menggunakan software startUML. Kami telah mempresentasikan spesifikasi desain teknis dan pembelajaran dari proyek baik secara visualisasi dan sistematik pada metode yang dipakai pada proses prediksi.Kami mempresentasikan arsitektur, komponen sistem menggunakan Bahasa UML, dengan visualisasi dalam use case diagram, class diagram, activity diagram serta sequence diagram. Hasil desain ini akan diimplementasikan pada pembuatan aplikasi baik secara visual maupun secara sistematik dengan memasukkan metode regresi linier.

\section{Daftar Pustaka}

Arifwicaksanaa. (2016, april 1). pengertian-use-case. Retrieved from medium.com: https://medium.com/@arifwicaksanaa/pengertian-use-case-a7e576e1b6bf

Bell, D. (2003, Juni 15). IBM. Retrieved from developerworks: https://www.ibm.com/developerworks/rational/library/769.html

Gabry, O. E. (2017, Maret 19). omarelgabrys-blog. Retrieved from medium.com: https://medium.com/omarelgabrys-blog/object-oriented-analysis-and-design-introduction-part-1a93b0ca69d36

John W. Satzinger, R. B. (2012). Sistems Analysis and Design in a Changing World. Joe Sabatino

L, S. (2011, Februari 21). what-is-a-design-system. Retrieved from medium.muz: https://medium.muz.li/what-is-a-design-system-1e43d19e7696

Pratama, A. R. (2016, agustus 11). mengenal-uml-contoh-uml-diagram-model-activity-diagram. Retrieved from www.codepolitan.com: https://www.codepolitan.com/mengenal-uml-contoh-umldiagram-model-activity-diagram

Satzinger, J. (2012). System Analysis and Design In a Changing World. Boston, USA: Course Technology. 